\title{
miR-28-3p inhibits prostate cancer cell proliferation, migration and invasion, and promotes apoptosis by targeting ARF6
}

\author{
JIABIN ZHANG ${ }^{*}$, YI YAO* , HUIZHANG LI and SHIHUA YE \\ Department of Urology, Mindong Hospital Affiliated to Fujian Medical University, \\ Ningde, Fujian 355000, P.R. China
}

Received November 28, 2019; Accepted June 28, 2021

DOI: $10.3892 /$ etm.2021.10639

\begin{abstract}
Previous studies have reported that the expression levels of microRNA (miR)-28-3p are downregulated in prostate cancer (PCa) compared with those in adjacent normal tissues. However, to the best of our knowledge, the function and underlying mechanisms of miR-28-3p in PCa have not been reported. The present study aimed to explore the role of miR-28-3p and its mechanism in the development of PCa. In the present study, miR-28-3p and ADP-ribosylation factor 6 (ARF6) expression levels were analyzed using reverse transcription-quantitative PCR (RT-qPCR). Cell proliferation, colony formation, apoptosis, migration and invasion were determined using Cell Counting Kit-8, colony forming, flow cytometry and Transwell assays, respectively. The association between miR-28-3p and ARF6 was investigated using a dual luciferase reporter assay. ARF6, Rac1, Erk1/2 and phosphorylated (p)-Erk1/2 protein expression levels were analyzed using western blotting. The results of the present study revealed that miR-28-3p expression levels were downregulated, whereas ARF6 expression levels were upregulated in PCa cell lines (LNCaP, 22Rv-1, PC-3 and DU145) compared with those in the normal prostate line RWPE-1. The overexpression of miR-28-3p promoted cell apoptosis, and inhibited cell proliferation, colony formation, migration and invasion. However, the knockdown of miR-28-3p exerted the opposite results. The results of the dual luciferase reporter assays, RT-qPCR and western blotting indicated that ARF6 was a target gene of miR-28-3p. Finally, rescue experiments demonstrated that ARF6 overexpression attenuated the effects of the miR-28-3p mimic by upregulating Rac1 and $\mathrm{p}$-Erk1/2 expression in $\mathrm{PCa}$ cells. In conclusion, these findings indicated that miR-28-3p
\end{abstract}

Correspondence to: Dr Jiabin Zhang, Department of Urology, Mindong Hospital Affiliated to Fujian Medical University, 89 Heshan Road, Ningde, Fujian 355000, P.R. China

E-mail: 616445896@qq.com

${ }^{*}$ Contributed equally

Key words: prostate cancer cells, microRNA-28-3p, ADP-ribosylation factor 6, Erk/Rac signaling pathway may inhibit the biological behaviors of PCa cells by targeting ARF6, and therefore may represent a novel therapeutic candidate for PCa.

\section{Introduction}

Prostate cancer is the second most commonly diagnosed cancer and the sixth leading cause of cancer-associated mortality among men worldwide, with an estimated 1,276,000 new prostate cancer cases and 359,000 deaths in 2018 (1). As PCa is an androgen-dependent cancer, where endocrine therapy (castration and antihormone therapy) is one of the main methods used to treat the disease (2). The majority of patients with $\mathrm{PCa}$ are initially responsive to androgen-deprivation therapy; however, this treatment not only increases the risk of dementia, but it may also induce PCa-related androgen receptor mutations $(3,4)$, which renders PCa difficult to treat. At present, to the best of our knowledge, the pathogenesis of PCa remains poorly understood. An enhanced understanding of the mechanisms involved in the occurrence and development of PCa will be of significant value to the early diagnosis, treatment and monitoring of the disease (5).

MicroRNAs (miRNAs/miRs) are a class of small non-coding RNAs that target specific mRNA sequences to inhibit protein translation (6). It has been reported that miRNAs are involved throughout the entire tumorigenesis process, where they have been closely associated with tumor cell proliferation, differentiation, invasion and metastasis (7). It has also been extensively reported that the expression levels of miRNAs in human cancer tissues are dysregulated (8). In fact, miRNAs have been proposed as alternative biomarkers and therapeutic tools for PCa prognosis and diagnosis (9). For example, miR-15a and miR-16 have been reported to function as tumor suppressors in PCa by inhibiting cell proliferation and invasion (10). In another study, miR-449a induced PCa cell cycle arrest by targeting histone deacetylase 1 (11). Furthermore, inhibitors of miR-346, miR-361-3p and miR-197 were found to significantly inhibit PCa migration and invasion (12).

Previously, Fuse et al (13) identified 56 downregulated miRNAs in PCa tissues in comparison to that in adjacent non-PCa tissues, including miR-28-3p. To the best of our knowledge, the role of miR-28-3p in PCa has not been reported. A previous study demonstrated that the knockdown 
of ADP-ribosylation factor 6 (ARF6) may exert an inhibitory effect on the hormone-independent PCa cell line, PC-3, and the molecular mechanisms associated with these changes were suggested to be due to the downregulation of phosphorylated (p)-Erk1/2 and Rac1 expression (14). In addition, the stable overexpression of the androgen driver tetraspanin 1 markedly promoted cell migration and upregulated the expression of ARF6 (15). However, it remains unclear whether miRNAs can target ARF6 in PCa.

The present study aims to explore the role of miR-28-3p and its mechanism in the development of PCa. miR-28-3p and ARF6 expression was quantified in both PCa tissues and cell lines. Based on these previous findings, the role of miR-28-3p and ARF6 in relation to the biological behaviors of PCa cells was investigated.

\section{Materials and methods}

Cell lines and culture. Four human PCa cell lines (LNCaP, 22Rv-1, PC-3 and DU145) and normal prostate cells (RWPE-1) were purchased from The Cell Bank of Type Culture Collection of The Chinese Academy of Sciences. PCa cell lines were cultured in RPMI-1640 medium (Gibco; Thermo Fisher Scientific, Inc.) supplemented with 10\% FBS (Gibco; Thermo Fisher Scientific, Inc.). RWPE-1 cells were cultured in serum-free RPMI-1640 medium (Gibco; Thermo Fisher Scientific, Inc.) containing bovine pituitary extract $(50 \mu \mathrm{g} / \mathrm{ml}$; Thermo Fisher Scientific, Inc.) and epidermal growth factor ( $5 \mathrm{ng} / \mathrm{ml}$, Invitrogen; Thermo Fisher Scientific, Inc.). All cells were maintained in a humidified atmosphere with $5 \% \mathrm{CO}_{2}$ at $37^{\circ} \mathrm{C}$.

Reverse transcription-quantitative PCR (RT-qPCR). Total RNA was extracted using $0.5 \mathrm{ml}$ NucleoZOL reagent (Gene Company, Ltd.) from LNCaP, 22Rv-1, PC-3, DU145 and RWPE-1 cells, according to the manufacturer's protocol. Total RNA was reverse transcribed into cDNA using a Prime Script $^{\mathrm{TM}}$ RT reagent kit (cat. no. DRR037A; Takara Bio, Inc.). The reverse transcription temperature protocol was as follows: $37^{\circ} \mathrm{C}$ for $15 \mathrm{~min}$ and $85^{\circ} \mathrm{C}$ for $5 \mathrm{sec}$. qPCR was subsequently performed using a SYBR Green Real-Time PCR Master mix (Thermo Fisher Scientific, Inc.). The following thermocycling conditions were used for qPCR: $50^{\circ} \mathrm{C}$ for $2 \mathrm{~min}$, initial denaturation at $95^{\circ} \mathrm{C}$ for $10 \mathrm{~min}$, followed by 40 cycles of $95^{\circ} \mathrm{C}$ for $30 \mathrm{sec}, 55^{\circ} \mathrm{C}$ for $1 \mathrm{~min}$ and $72^{\circ} \mathrm{C}$ for $30 \mathrm{sec}$. The following primer sequences were used for qPCR: miR-28-3p forward, 5'-CGCGCACTAGATTGTGAGCT-3' and reverse, 5'-AGT GCAGGGTCCGAGGTATT-3'; U6 forward, 5'-CTCGCT TCGGCAGCACATATACT-3' and reverse, 5'-ACGCTTCAC GAATTTGCGTGTC-3'; ARF6 forward, 5'-GCGGCATTA CTACACTGGGA-3' and reverse, 5'-CCTGGATCTCGTGGG GTTTC-3'; and GAPDH forward, 5'-GTCAAGGCTGAGAAC GGGAA-3' and reverse, 5'-AAATGAGCCCCAGCCTTC TC-3' miR-28-3p expression was normalized to U6 expression levels, whereas ARF6 expression was normalized to GAPDH expression levels. Relative gene expression was calculated using the $2^{-\Delta \Delta \mathrm{Cq}}$ method (16).

Cell transfection. The miR-28-3p mimic (5'-CACUAGAUU GUGAGCUCCUGGA-3'), mimic negative control (NC;
5'-UCUACUCUUUCUAGGAGGUUGUGA-3'), miR-28-3p inhibitor (5'-UCC AGGAGC UCACAAUCUAGUG-3') and inhibitor NC (5'-UCUACUCUUUCUAGGAGGUUG UGA-3') were obtained from Shanghai GenePharma Co., Ltd. The ARF6 gene was synthesized and then cloned into the pcDNA3.1 vector (Thermo Fisher Scientific, Inc.). To construct the pcDNA-ARF6 recombinant plasmid. Transfection of the empty vector pcDNA3.1 was used as negative control (pcDNA). DU145 cells were seeded at a density of $1 \times 10^{5}$ cells/well in 24-well plates. Transfection of each oligonucleotide or plasmid into DU145 cells was performed using Lipofectamine ${ }^{\circledR} 2000$ (Invitrogen; Thermo Fisher Scientific, Inc.) according to the manufacturer's protocol. Briefly, $5 \mu$ l Lipofectamine 2000 was incubated in $250 \mu \mathrm{l}$ serum-free RPMI-1640 medium for $5 \mathrm{~min}$ at $37^{\circ} \mathrm{C}$. An appropriate amount of miR-28-3p mimic $(25 \mathrm{nM})$, miR-28-3p inhibitor $(50 \mathrm{nM})$, mimic $\mathrm{NC}(25 \mathrm{nM})$, inhibitor NC $(50 \mathrm{nM})$, pcDNA $(2 \mu \mathrm{g})$ or pcDNA-ARF6 $(2 \mu \mathrm{g})$ was added and incubated for a further $20 \mathrm{~min}$ at room temperature. Following the incubation, the final mixture was added to each well and incubated at $37^{\circ} \mathrm{C}$ with cells for $48 \mathrm{~h}$. Subsequently, cells were used for the follow-up experiments.

Cell Counting Kit-8 (CCK-8) assay. Cell proliferation was analyzed using CCK-8 reagent (Beyotime Institute of Biotechnology). Briefly, cells were seeded into 96-well plates at a density of $1 \times 10^{3}$ cells/well and cultured for 0,24 , 48,72 or $96 \mathrm{~h}$. Following the incubation, $10 \mu \mathrm{l} \mathrm{CCK}-8$ solution was added to each well and further incubated for $2 \mathrm{~h}$ at $37^{\circ} \mathrm{C}$. The absorbance was measured at a wavelength of $450 \mathrm{~nm}$ using a microplate reader.

Colony formation assay. Cell proliferation was also analyzed using a colony forming assay. Briefly, transfected cells in the logarithmic growth phase were collected, and 800 cells/well were plated into a 6 -well plate and incubated at $37^{\circ} \mathrm{C}$. The state of the cells was observed until the number of cells in the majority of the individual colonies in the well was $\geq 50$. Following the incubation, the cells were fixed with $4 \%$ paraformaldehyde at $4^{\circ} \mathrm{C}$ for $1 \mathrm{~h}$ and stained with clean, impurity-free $0.1 \%$ crystal violet dye solution for a further $2 \mathrm{~min}$ at room temperature. Images of colonies were captured with a digital camera and counted.

Flow cytometric analysis of apoptosis. Flow cytometry was performed to detect cell apoptosis using an Annexin V-fluorescein isothiocyanate apoptosis measurement kit (BD Biosciences). Briefly, following transfection, the cells $\left(1 \times 10^{6} / \mathrm{m}\right)$ were washed twice with cold PBS, and stained with $5 \mu 1$ Annexin $\mathrm{V}$ and $10 \mu \mathrm{l}$ PI for $15 \mathrm{~min}$ in the dark at room temperature. Apoptotic cells were analyzed using a BD FACSVerse ${ }^{\mathrm{TM}}$ flow cytometer (BD Biosciences) and data were analyzed with the FlowJo software Version 10 (FlowJo LLC). The percentage of early and late apoptotic cells was calculated.

Transwell assays. The migratory and invasive abilities of cells were analyzed using Transwell assays. For the migration assays, cells were seeded into 24 -well plates, before $1 \times 10^{5}$ cells suspended in serum-free RPMI-1640 medium were added to the upper chambers of Transwell plates (Corning, Inc.), whilst 
RPMI-1640 medium supplemented with 20\% FBS was added to the lower chamber. After $24 \mathrm{~h}$ of incubation at $37^{\circ} \mathrm{C}$, the cells remaining in the upper chamber were removed with a cotton swab, while cells that had migrated to the lower chamber were fixed with $4 \%$ paraformaldehyde for $0.5 \mathrm{~h}$ at room temperature and stained with $0.5 \%$ crystal violet for $15 \mathrm{~min}$ at room temperature. Migratory cells from each group were visualized and counted in three randomly selected fields of view using a light microscope (magnification, $\mathrm{x} 400$; Olympus Corporation). The percentage migrated area was calculated with Image Pro Plus 6.0 (Media Cybernetics, Inc.).

For the cell invasion assays, the upper chambers of the 24-well Transwell plates were precoated with standard Matrigel (BD Biosciences) diluted 1:8 in serum-free medium, and were air-dried at $4^{\circ} \mathrm{C}$ and thoroughly solidified at $37^{\circ} \mathrm{C}$ for $30 \mathrm{~min}$. Subsequently, $100 \mu \mathrm{l}$ cells from each group suspended in serum-free medium were plated at a density of $1 \times 10^{5}$ cells $/ \mathrm{ml}$ into the upper chambers of. The remaining steps are consistent with those aforementioned for the migration assay.

Vector construction and dual luciferase reporter assay. To determine potential target genes of miR-28-3p, TargetScan 7.2 (http://www.targetscan.org/vert_72/) was used. According to the sequence of the ARF6 3'-untranslated region (UTR) found in GenBank (accession no. NM_001663.4), primers were designed and ARF6 was amplified (The template cDNA was obtained from 293T cells) using PrimerSTAR ${ }^{\circledR}$ Max DNA Polymerase (cat. no. R045A; Takara Biotechnology Co., Ltd.) and cloned into the psiCHECK ${ }^{\mathrm{TM}}-2$ dual luciferase reporter vector (Promega Corporation) to construct a wild-type (WT) dual-luciferase recombinant plasmid (ARF6-WT). The following primer sequences were used for amplified: forward, 5'-CCTCGAGTGACTTCCAGCAGATGGGAT G-3' and reverse, 5'-ATTTGCGGCCGCACATACTGAGGT GCAACTGGA-3'. The following thermocycling conditions were used for qPCR: Initial denaturation at $95^{\circ} \mathrm{C}$ for $5 \mathrm{~min}$, denaturation at $95^{\circ} \mathrm{C}$ for $30 \mathrm{sec}$, followed by 32 cycles of $55^{\circ} \mathrm{C}$ for $30 \mathrm{sec}, 72^{\circ} \mathrm{C}$ for $45 \mathrm{~s}$ and $72^{\circ} \mathrm{C}$ for $10 \mathrm{sec}$. ARF6-Mut were synthesized by Universal biological systems (Anhui) Co., Ltd. (https://www.generalbiol.com/) by mutating the specific binding sequence for miR-28-3p in the 3'-UTR of ARF6. 293 T cells purchased from The Cell Bank of Type Culture Collection of The Chinese Academy of Sciences and were cultured in DMEM (Invitrogen; Thermo Fisher Scientific, Inc.) supplemented with 10\% FBS (Gibco; Thermo Fisher Scientific, Inc.) at $37^{\circ} \mathrm{C}$ under $5 \% \mathrm{CO}_{2} .293 \mathrm{~T}$ cells $\left(1 \times 10^{6}\right)$ were cultured in 12 -well plates for $24 \mathrm{~h}$ at $37^{\circ} \mathrm{C}$. Subsequently, $20 \mu \mathrm{M}$ miR-28-3p mimic or miR-28-3p inhibitor and $50 \mathrm{ng}$ ARF6-WT or -Mut reporter plasmids were transfected into the cells using Lipofectamine ${ }^{\circledR} 2000$ at $37^{\circ} \mathrm{C}$. Cells transfected with $20 \mu \mathrm{M}$ mimic NC or inhibitor NC and 50 ng ARF6-WT or -Mut reporter plasmids were used as control groups. A total of $48 \mathrm{~h}$ post-transfection, a Dual Luciferase Reporter assay system (Promega Corporation) was used to measure the relative luciferase activity. Firefly luciferase activity was normalized to Renilla luciferase activity.

Western blotting. Total protein was extracted from collected cells in RIPA buffer (Sigma-Aldrich; Merck KGaA) containing $1 \mathrm{mM}$ PMSF (Sigma-Aldrich; Merck KGaA) and total protein concentration was quantified using a $\mathrm{BCA}$ assay (Beyotime Institute of Biotechnology). In total, $20 \mu \mathrm{g}$ proteins were separated by $10 \%$ SDS-PAGE and subsequently transferred onto a PVDF membrane (EMD Millipore), which was blocked with $5 \%$ bovine serum albumin (Sigma-Aldrich; Merck KGaA) diluted in TBS- $0.1 \%$ Tween-20 buffer at room temperature for $2 \mathrm{~h}$. The membranes were then incubated with the following primary antibodies (all 1:1,000) at $4^{\circ} \mathrm{C}$ overnight: Anti-ARF6 (Abcam; cat. no. ab226389), anti-Rac1 (Abcam; cat. no. ab155938), anti-Bcl-2 (Abcam; cat. no. ab194583), anti-Bax (Abcam; cat. no. ab263897), anti-Erk1/2 (Abcam; cat. no. ab17942), anti-p-ERK1/2 (Abcam; cat. no. ab214362) and anti- $\beta$-actin (Abcam; cat. no. ab213262). Following the primary antibody incubation, the membranes were washed with TBST and incubated with a HRP-conjugated secondary antibody (Abcam; cat. no. ab6721; 1:5,000) at room temperature for $2 \mathrm{~h}$. Protein bands were visualized using SuperSignal ${ }^{\mathrm{TM}}$ West Pico PLUS Chemiluminescent Substrate (Thermo Fisher Scientific, Inc.; cat. no. 34080) on a VersaDoc ${ }^{\mathrm{TM}}$ gel imaging system (Bio-Rad Laboratories, Inc.). Densitometric analysis was performed using the Image J software (version 1.51; National Institutes of Health).

Statistical analysis. Statistical analysis was performed using GraphPad Prism software version 5.0 (GraphPad Software, Inc.) and data are presented as the mean \pm SD. Statistical differences between groups were analyzed using a one-way ANOVA followed by a Tukey's post hoc test. $\mathrm{P}<0.05$ was considered to indicate a statistically significant difference. All experiments were repeated three times.

\section{Results}

Expression levels of miR-28-3p and ARF6 in human $P C a$ cell lines. To investigate the role of miR-28-3p and ARF6 in human PCa cell lines, miR-28-3p and ARF6 expression levels were analyzed in four PCa cell lines (LNCaP, 22Rv-1, PC-3 and DU145). Compared with those detected in RWPE-1 cells, the expression levels of miR-28-3p were significantly downregulated in the four PCa cell lines (Fig. 1A), and DU145 cells exhibited the greatest decrease in miR-28-3p expression. Conversely, the mRNA expression levels of ARF6 were significantly upregulated in the four PCa cell lines compared with those in RWPE-1 cells (Fig. 1B), and DU145 cells had the highest expression levels of ARF6. Therefore, DU145 cells were selected for use in subsequent experiments, including the establishment of miR-28-3p mimic-/inhibitor-transfected cells.

Transfection efficiency of miR-28-3p inhibitor and mimic in DU145 cells. To determine the role of miR-28-3p in PCa cells, the human PCa cell line, DU145, was transfected with the miR-28-3p mimic, which is a chemically synthesized double-stranded oligonucleotide that mimics the endogenous mature function of miR-28-3p, or a miR-28-3p inhibitor, which is a modified antisense oligonucleotide that inhibits miR-28-3p function. Cells transfected with the mimic NC or inhibitor NC were used as controls. A total of $48 \mathrm{~h}$ post-transfection, the expression levels of miR-28-3p were determined using RT-qPCR. The results revealed that 

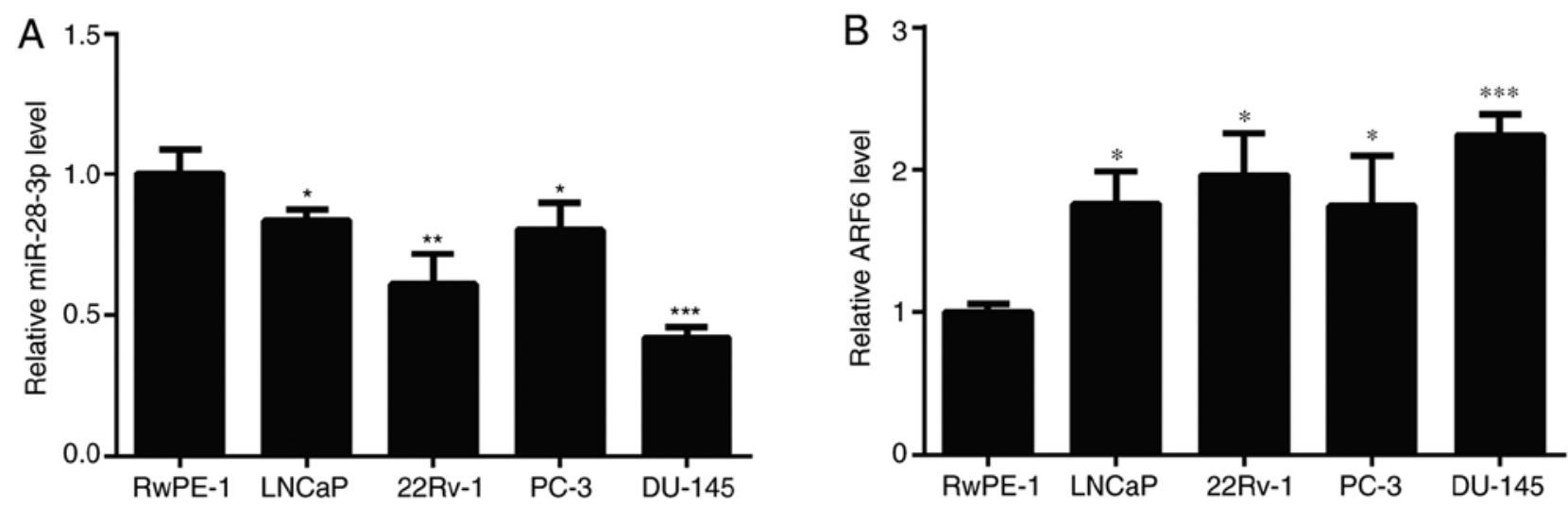

Figure 1. Relative miR-28-3p and ARF6 expression levels in PCa cell lines. Expression levels of (A) miR-28-3p and (B) ARF6 in PCa cell lines were analyzed using reverse transcription-quantitative PCR. miR-28-3p expression was significantly downregulated, whereas ARF6 expression was significantly upregulated in PCa cell lines compared with those in the RWPE-1 cells. ${ }^{*} \mathrm{P}<0.05,{ }^{* *} \mathrm{P}<0.01,{ }^{* * *} \mathrm{P}<0.001$ vs. RWPE-1 cells. miR, microRNA; ARF6, ADP-ribosylation factor 6; PCa, prostate cancer.

transfection with the miR-28-3p mimic upregulated the expression levels of miR-28-3p by $\sim 30$-fold, whereas transfection with the miR-28-3p inhibitor downregulated the expression of miR-28-3p in DU145 cells compared with those in cells transfected with the respective NCs (Fig. 2). These results indicated that the miR-28-3p mimic and inhibitor were able to effectively regulate miR-28-3p expression levels in DU145 cells.

Effect of miR-28-3p on the proliferation of DU145 cells. The effects of miR-28-3p on the proliferation of DU145 cells were determined using a CCK- 8 assay. The results demonstrated that the proliferation of miR-28-3p mimic-transfected cells was significantly decreased compared with the mimic NC-transfected cells (Fig. 3A). Conversely, the knockdown of miR-28-3p expression in cells significantly increased the proliferation compared with the inhibitor NC-transfected cells (Fig. 3A). To further analyze cell proliferation, colony formation experiments were performed. The results revealed that the number of colonies was significantly decreased in the miR-28-3p mimic group compared with that in the mimic NC group (Fig. 3B and C). Compared with the inhibitor NC group, the number of colonies was significantly increased in the miR-28-3p inhibitor group.

Effect of miR-28-3p on the apoptosis of DU145 cells. A total of $48 \mathrm{~h}$ post-transfection with the miR-28-3p mimic or inhibitor, cell apoptosis was determined by flow cytometry. The results revealed that the apoptotic rate was significantly increased in the miR-28-3p mimic group compared with that in the mimic NC group (Fig. 4A). Compared with the inhibitor NC group, the apoptotic rate was significantly decreased in the miR-28-3p inhibitor group. In addition, the ratio of $\mathrm{Bcl}-2 / \mathrm{Bax}$ was detected by western blotting. The results revealed that miR-28-3p overexpression reduced the $\mathrm{Bcl}-2 / \mathrm{Bax}$ ratio, which may aggravate apoptosis, whereas inhibition of miR-28-3p expression upregulated the $\mathrm{Bcl}-2 / \mathrm{Bax}$ ratio, which could inhibit apoptosis (Fig. 4B).

Effect of miR-28-3p on the migration and invasion of DU145 cells. Whether miR-28-3p regulated human PCa cell migration

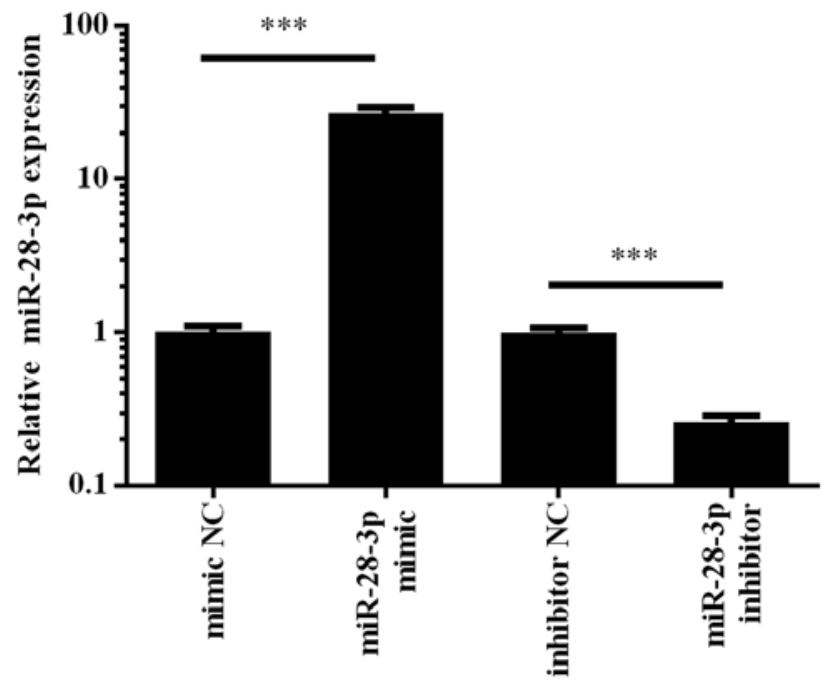

Figure 2. Establishment of miR-28-3p-knockdown and -overexpressing DU145 cells. Reverse transcription-quantitative PCR analysis revealed that the miR-28-3p mimic significantly upregulated the expression of miR-28-3p, whereas the miR-28-3p inhibitor significantly downregulated miR-28-3p expression. ${ }^{* * *} \mathrm{P}<0.001$. miR, microRNA; NC, negative control.

and invasion was investigated in the PCa cell line, DU145, following transfection with the miR-28-3p mimic, miR-28-3p inhibitor, mimic NC or inhibitor NC. The results revealed that the migratory and invasive abilities of DU145 cells were significantly decreased in the miR-28-3p mimic group compared with those in the mimic NC group (Fig. 5). By contrast, the migration and invasion were significantly increased in the miR-28-3p inhibitor group compared with those in the inhibitor NC group (Fig. 5). These results indicated that miR-28-3p may be a negative regulator of PCa migration and invasion.

ARF6 is a direct target gene of $m i R-28-3 p$. TargetScan was used to predict the potential gene target of miR-28-3p. The 3'-UTR of ARF6 was identified to contain a complementary site for the seed region of miR-28-3p (Fig. 6A). To further validate whether miR-28-3p targeted ARF6, a dual luciferase reporter assay was used to determine the relationship between miR-28-3p and ARF6 in the 293T cell line. As 
A

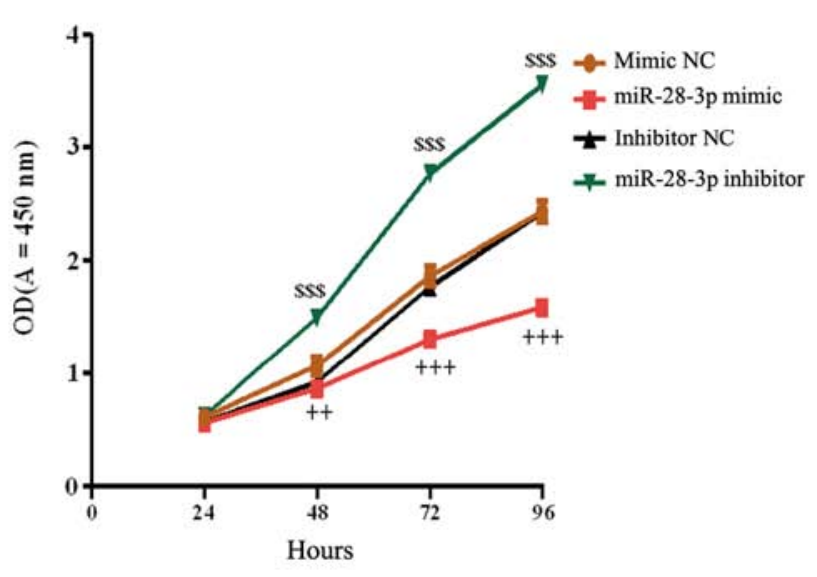

C

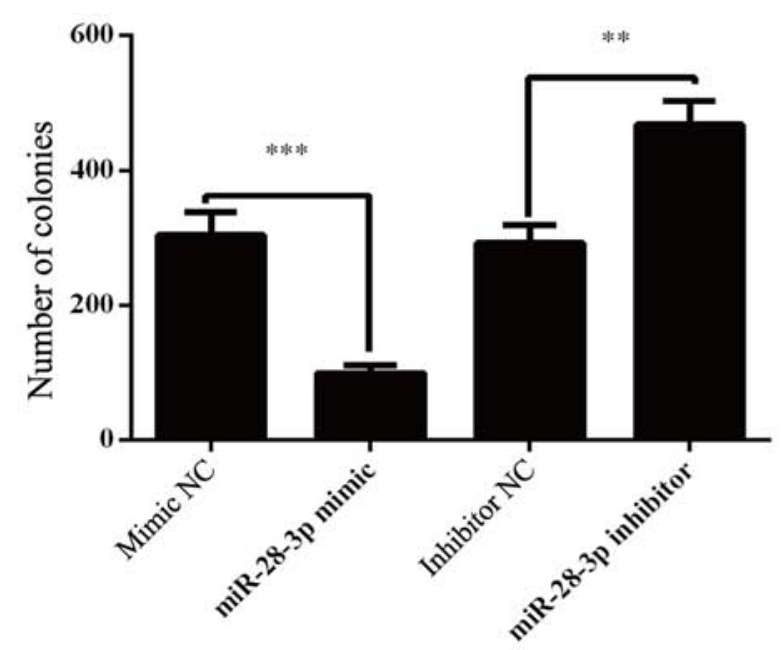

B

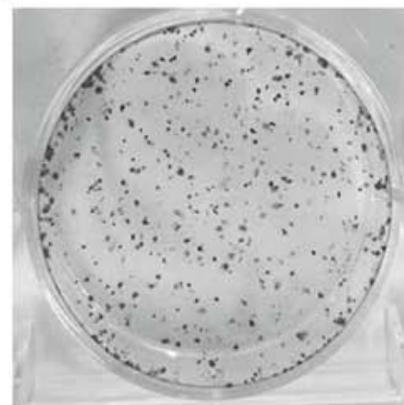

Mimic NC

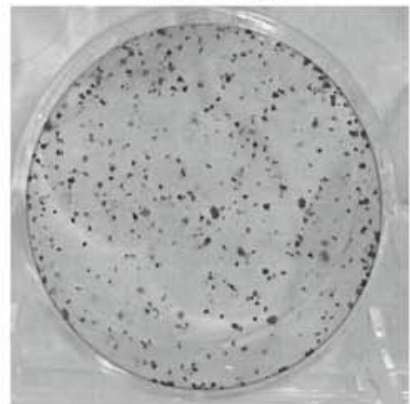

Inhibitor NC

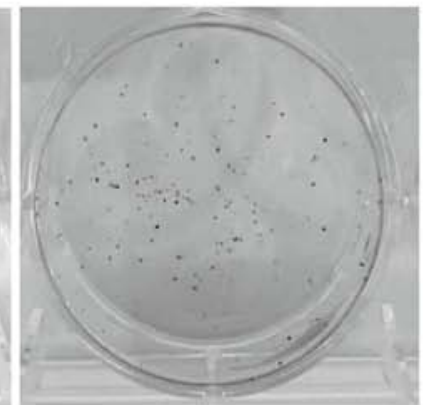

miR-28-3p mimic

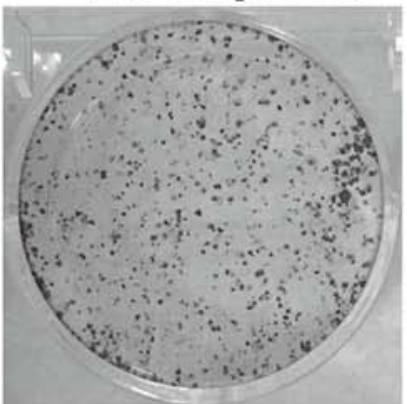

miR-28-3p inhibitor

Figure 3. Proliferation of DU145 cells following transfection with miR-28-3p mimic or inhibitor. (A) Cell Counting Kit-8 assay was performed to determine the effect of the miR-28-3p inhibitor or mimic on cell proliferation. (B) Colony forming assays were performed to observe the formation of cell colonies. (C) Semi-quantification of the results from (B). Compared with the respective NC group, the miR-28-3p mimic inhibited the formation of cell colonies, whereas the miR-28-3p inhibitor significantly increased the formation of colonies. ${ }^{++} \mathrm{P}<0.01$ and ${ }^{+++} \mathrm{P}<0.001 \mathrm{vs}$. mimic $\mathrm{NC} ;{ }^{\$ \$} \mathrm{P}<0.001$ vs. inhibitor $\mathrm{NC} ;{ }^{* *} \mathrm{P}<0.01$, ${ }^{* * * *} \mathrm{P}<0.001$. microRNA; NC, negative control; OD, optical density.

illustrated in Fig. 6A, transfection with the miR-28-3p mimic significantly decreased the relative luciferase activity of the ARF6-WT 3'-UTR compared with that in cells following the transfection of mimic NC. Transfection with the miR-28-3p inhibitor significantly increased the relative luciferase activity of the ARF6-WT 3'-UTR compared with that in cells after the transfection of inhibitor NC. Furthermore, these effect was abolished when the nucleotides in the seed binding site of the ARF6 3'-UTR were mutated. Moreover, the effect of miR-28-3p on the expression levels of ARF6 was analyzed using RT-qPCR and western blotting. The results revealed that overexpression of miR-28-3p significantly downregulated the mRNA expression levels of ARF6 in DU145 cells compared with those in the mimic NC-transfected cells
(Fig. 6B). Conversely, knockdown of miR-28-3p significantly upregulated the mRNA expression levels of ARF6 compared with those in the inhibitor NC-transfected cells (Fig. 6B). In addition, overexpression of miR-28-3p significantly downregulated the protein expression levels of ARF6 in DU145 cells compared with those in the mimic NC-transfected cells, whereas knockdown of miR-28-3p significantly upregulated the protein expression levels of ARF6 compared with those in the inhibitor NC-transfected cells (Fig. 6C). These results suggested that ARF6 may be a direct target gene of miR-28-3p.

Effect of ARF6 and miR-28-3p overexpression on DU145 cells. The transfection efficiency of pcDNA-ARF6 was 
A
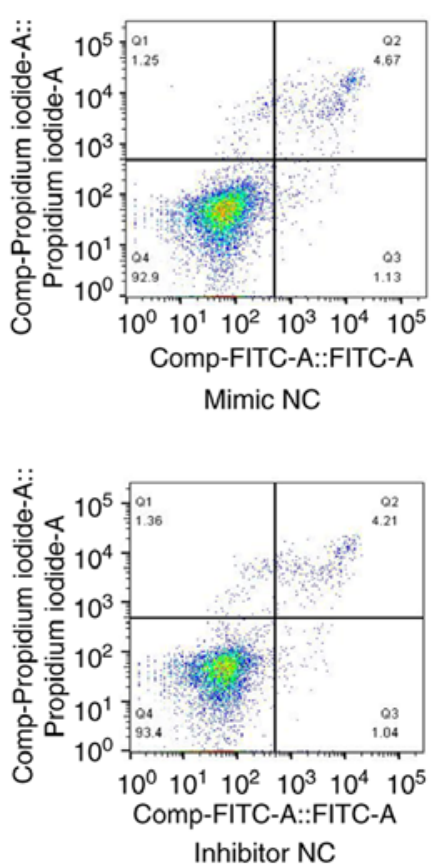
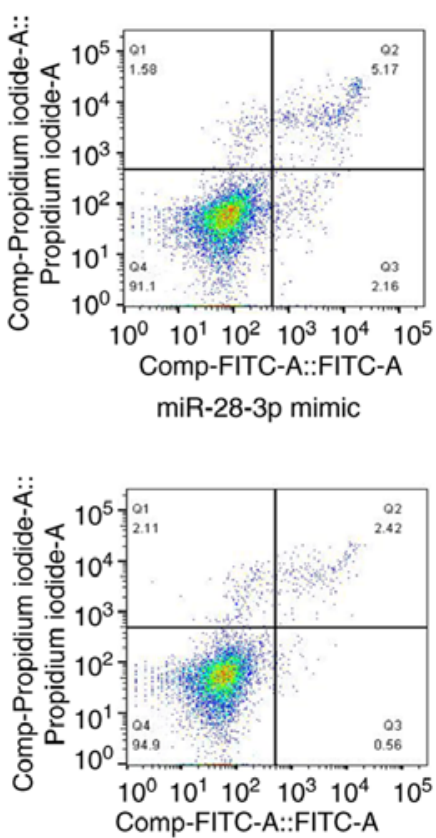

miR-28-3p inhibitor

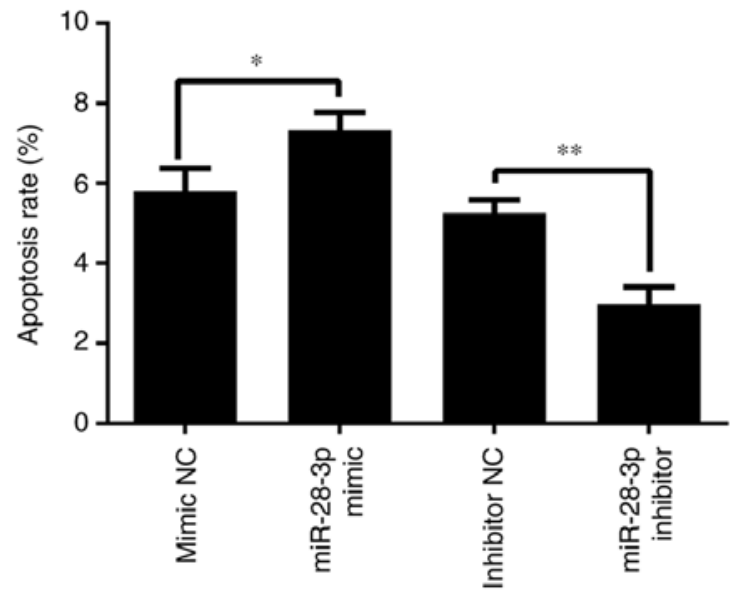

B

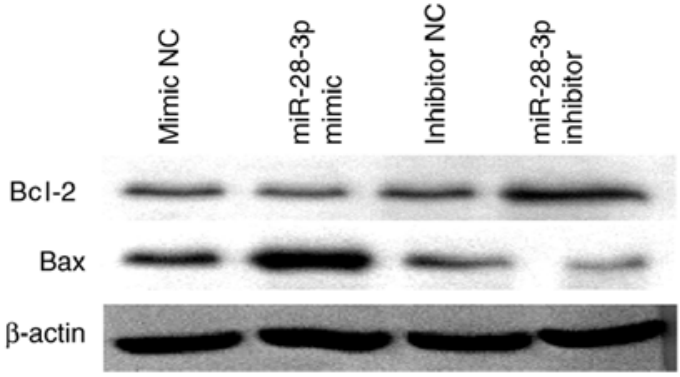

Figure 4. Apoptosis of DU145 cells following transfection with miR-28-3p mimic or inhibitor. (A) Flow cytometry was used to detect cell apoptosis. Compared with the mimic NC group, the miR-28-3p mimic significantly increased the apoptotic rate, whereas the miR-28-3p inhibitor significantly inhibited apoptosis (B) Western blotting was used to detect the expression of protein related with cell apoptosis. miR-28-3p mimic reduced the Bcl-2/Bax ratio, whereas miR-28-3p inhibitor upregulated the Bcl-2/Bax ratio. ${ }^{*} \mathrm{P}<0.05,{ }^{* *} \mathrm{P}<0.01,{ }^{* * *} \mathrm{P}<0.001$. miR, microRNA; NC, negative control.

validated using RT-qPCR (Fig. 7A). As expected, the expression levels of ARF6 in cells transfected with pcDNA-ARF6 were significantly upregulated compared with those in the pcDNA-transfected cells. To investigate the effect of ARF6 on the miR-28-3p mimic-transfected DU145 cells, pcDNA-ARF6 was transfected into miR-28-3p mimic-transfected DU145 cells. The results of the CCK- 8 assay demonstrated that the overexpression of ARF6 significantly attenuated the miR-28-3p mimic-induced inhibitory effect on cell proliferation (Fig. 7B), which was consistent with the results of the cell colony formation assay $(\mathrm{P}<0.05$; Fig. 7C and D).

Apoptosis was further determined by flow cytometry and western blotting after co-transfecting cells with miR-28-3p mimic and pcDNA-ARF6 for $48 \mathrm{~h}$. The results revealed that the apoptotic rate was significantly decreased
(Fig. 8A) and the ratio of Bcl-2/Bax was markedly elevated (Fig. 8B) following co-transfection compared with that in the miR-28-3p mimic-transfected group; however, the apoptotic rate was not completely recovered to the same levels as the control. Finally, migratory and invasive abilities were determined using Transwell assays. The results showed that the overexpression of ARF6 in miR-28-3p mimic-transfected cells promoted both migration $(\mathrm{P}<0.01)$ and invasion $(\mathrm{P}<0.01)$ compared with those in the miR-28-3p mimic group (Fig. 9). These findings suggested that AFR6 may attenuate miR-28-3p mimic-induced inhibitory effects.

Effect of miR-28-3p overexpression and knockdown on p-Erk1/2 and Racl expression. To further determine the molecular mechanism of the miR-28-3p-mediated biological functions, the effect of miR-28-3p overexpression and 
A

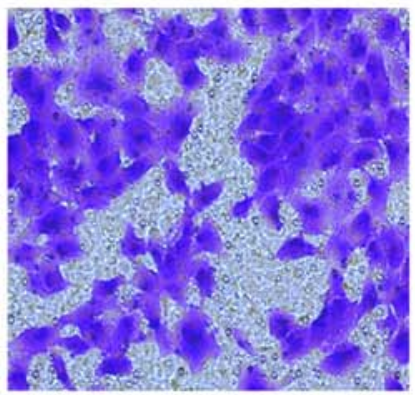

Mimic NC

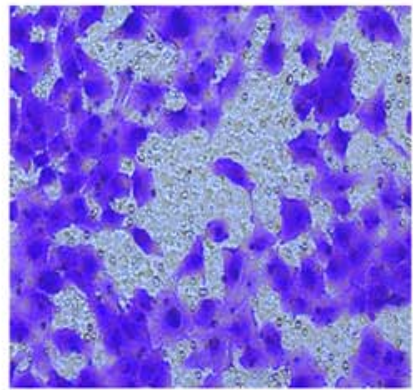

Inhibitor NC

B
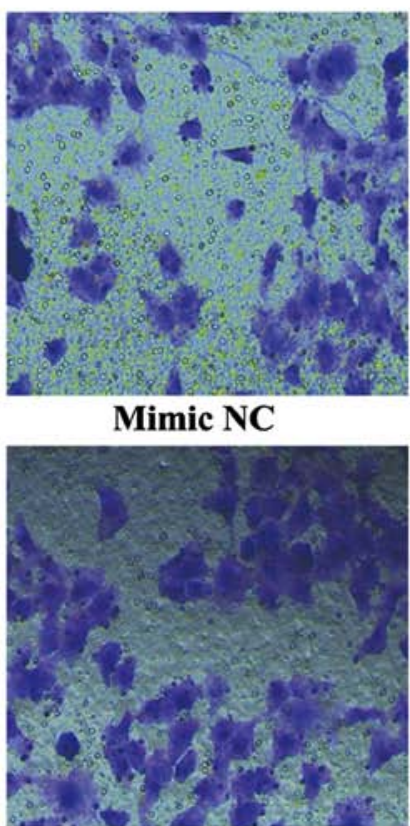

Inhibitor NC

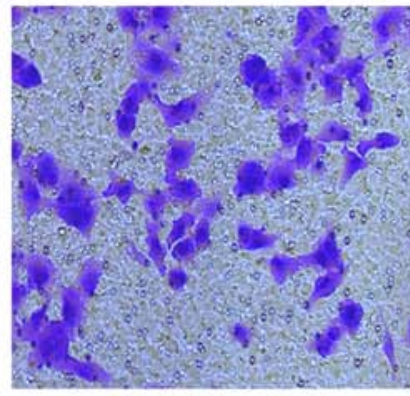

miR-28-3p mimic

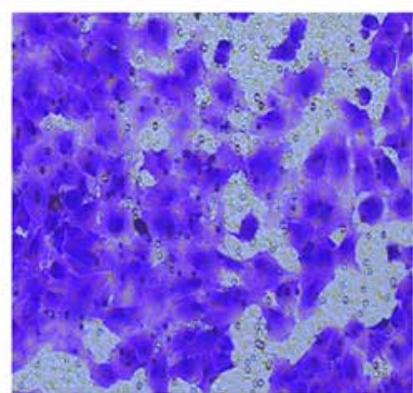

miR-28-3p inhibitor

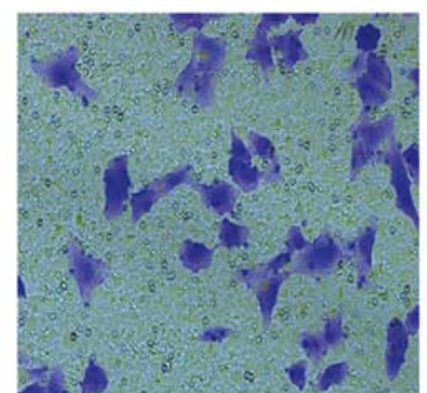

miR-28-3p mimic

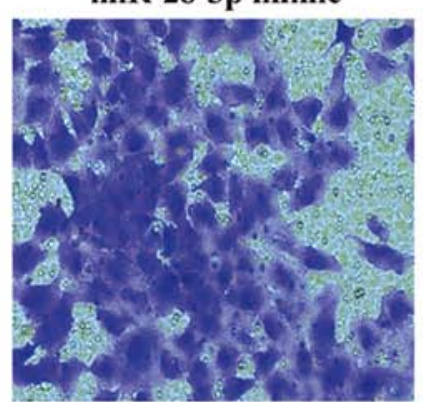

miR-28-3p inhibitor

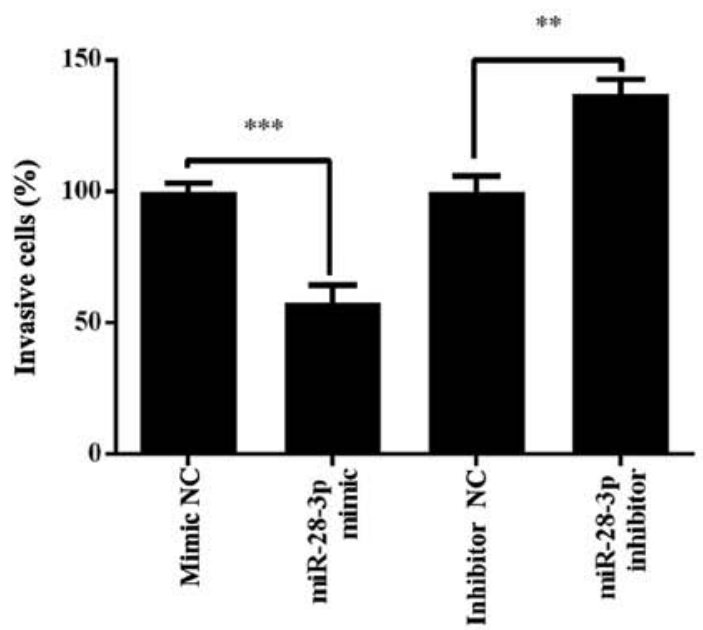

Figure 5. Migration and invasion of DU145 cells following transfection with miR-28-3p mimic or inhibitor. (A) Cell migration and (B) invasion were measured using Transwell assays. Compared with the respective NC group, the miR-28-3p mimic significantly inhibited the migratory ability of DU145 cells, whereas the miR-28-3p inhibitor increased cell migration. The invasion of the miR-28-3p mimic group was significantly decreased compared with that in the mimic NC group, whereas the miR-28-3p inhibitor significantly enhanced cell invasion compared with the inhibitor $\mathrm{NC}$ group. Magnification, $\mathrm{x} 400 .{ }^{* *} \mathrm{P}<0.01,{ }^{* * *} \mathrm{P}<0.001$. miR, microRNA; NC, negative control.

knockdown on p-Erk1/2 and Rac1 expression was analyzed. The results demonstrated that the overexpression of miR-28-3p significantly downregulated the protein expression levels of p-Erk1/2/Erk1/2 and Rac1 in DU145 cells compared with those in the mimic NC-transfected cells, but exerted no effect on Erk1/2 expression (Fig. 10). Meanwhile, the knockdown of miR-28-3p significantly upregulated the protein expression levels of $\mathrm{p}$-Erk1/2/Erk1/2 and Rac1 compared with those in the inhibitor NC-transfected cells, but had no effect on Erk1/2 expression.

Effect of ARF6 and miR-28-3p overexpression on p-Erkl/2 and Racl. To further determine the mechanism by which miR-28-3p and ARF6 affected the biological functions of PCa 


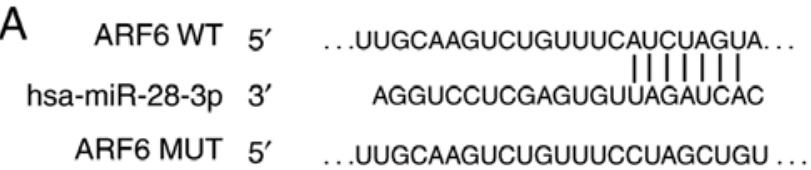
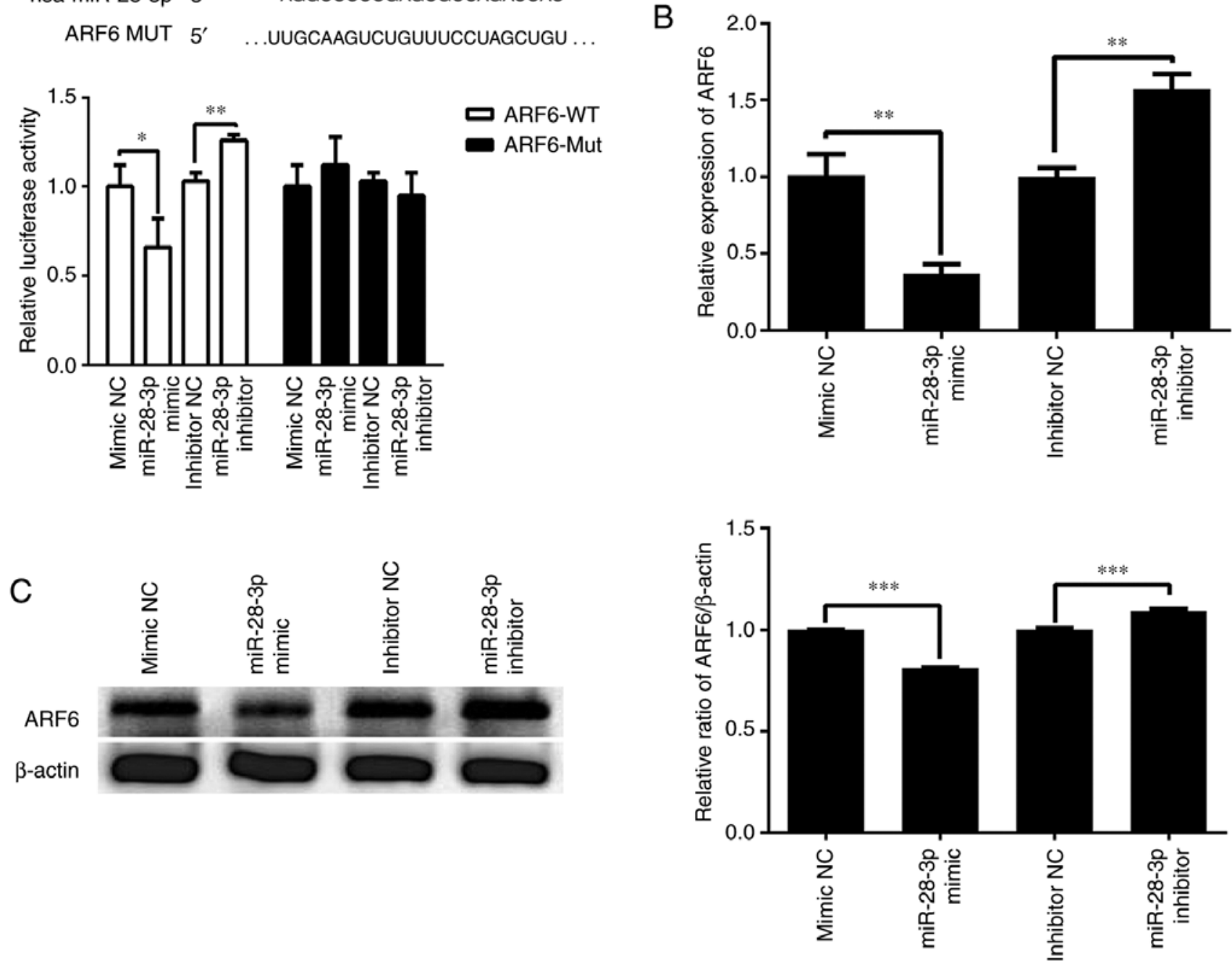

Figure 6. ARF6 is a direct target gene of miR-28-3p. (A) Prediction of miR-28-3p binding sites in the 3'-untranslated region of the ARF6 gene was performed using TargetScan. Dual luciferase reporter gene assay was used to verify the miR-28-3p target gene. Transfection with the miR-28-3p mimic reduced the WT luciferase activity, whereas transfection with the miR-28-3p inhibitor significantly increased the WT luciferase activity. The luciferase activity of the Mut cells was not significantly altered from that of the inhibitor NC or mimic NC groups. (B) Reverse transcription-quantitative PCR was used to analyze the expression levels of ARF6 in DU145 cells following transfection with the miR-28-3p mimic or inhibitor. (C) Western blotting was used to analyze the effects of miR-28-3p on ARF6 protein expression levels. ${ }^{*} \mathrm{P}<0.05,{ }^{* *} \mathrm{P}<0.01,{ }^{* * *} \mathrm{P}<0.001$. ARF6, ADP-ribosylation factor 6; miR, microRNA; WT, wild-type; Mut, mutant; NC, negative control.

cells, the effect of the overexpression of these two factors on p-Erk1/2 and Rac1 expression was investigated. As shown in Fig. 11, the results revealed that transfection with the miR-28-3p mimic significantly downregulated the protein expression levels of Rac1 and p-Erk1/2/Erk1/2, without altering total Erk1/2 expression. Notably, the co-overexpression of ARF6 partially reversed the effects of the miR-28-3p mimic on Rac and $p$-Erk $1 / 2$ expression. Thus, miR-28-3p and ARF6 may mediate the Erk signaling pathway.

\section{Discussion}

$\mathrm{PCa}$ is a malignant epithelial tumor that occurs in the prostate (17). Numerous miRNAs, such as miR-1, miR-21, miR-106b, miR-141, miR-145, miR-205, miR-221 and miR-375 (18), have been reported to be implicated in PCa progression. Among them, miR-28-3p was discovered to play a major role in several tumor types. For example, the overexpression of miR-28-3p increased the migration and invasion of colorectal cancer cells in vitro (19). Another previous study found that the expression levels of miR-28-3p were significantly upregulated in esophageal squamous cell carcinoma (ESCC) tissues and it was therefore suggested to be a potential novel serum miRNA marker to screen for ESCC (20). In addition, some miRNAs in urine supernatants, including miR-28-3p, were found to be potential noninvasive markers for bladder cancer diagnosis (21). Fuse et al (13) screened 56 downregulated miRNAs in PCa tissues in comparison to non-PCa tissues and discovered that miR-222 and miR-31 inhibited the proliferation, invasion and migration of the hormone-independent $\mathrm{PCa}$ cell lines, PC3 and DU145. Nevertheless, to the best of our knowledge, the role of miR-28-3p in PCa remains unclear. 
A

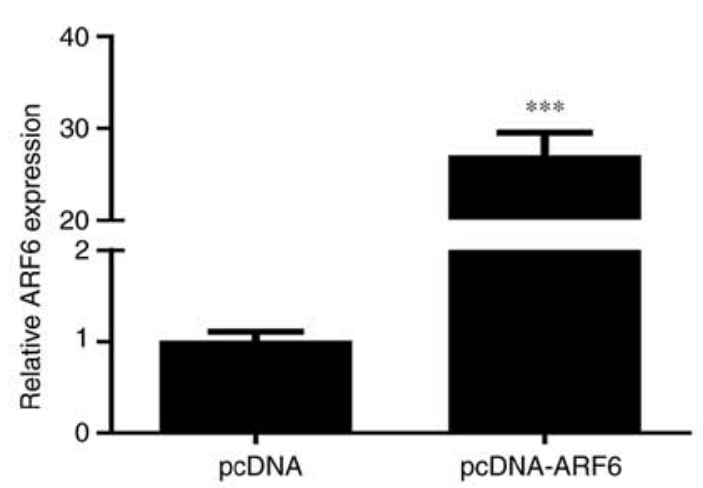

C

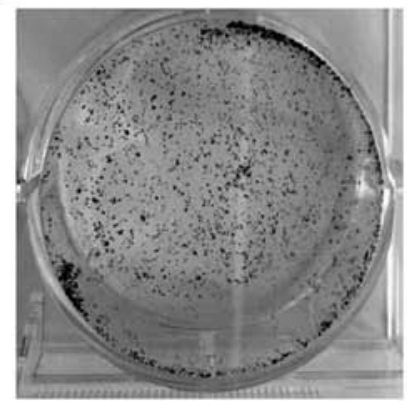

Mimic NC

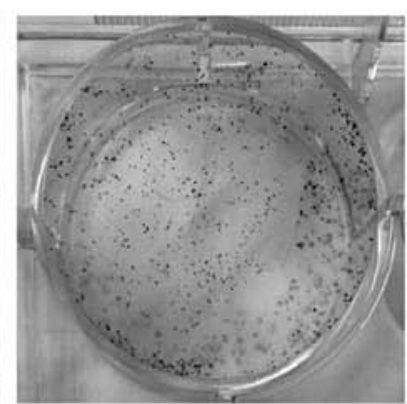

miR-28-3p mimic
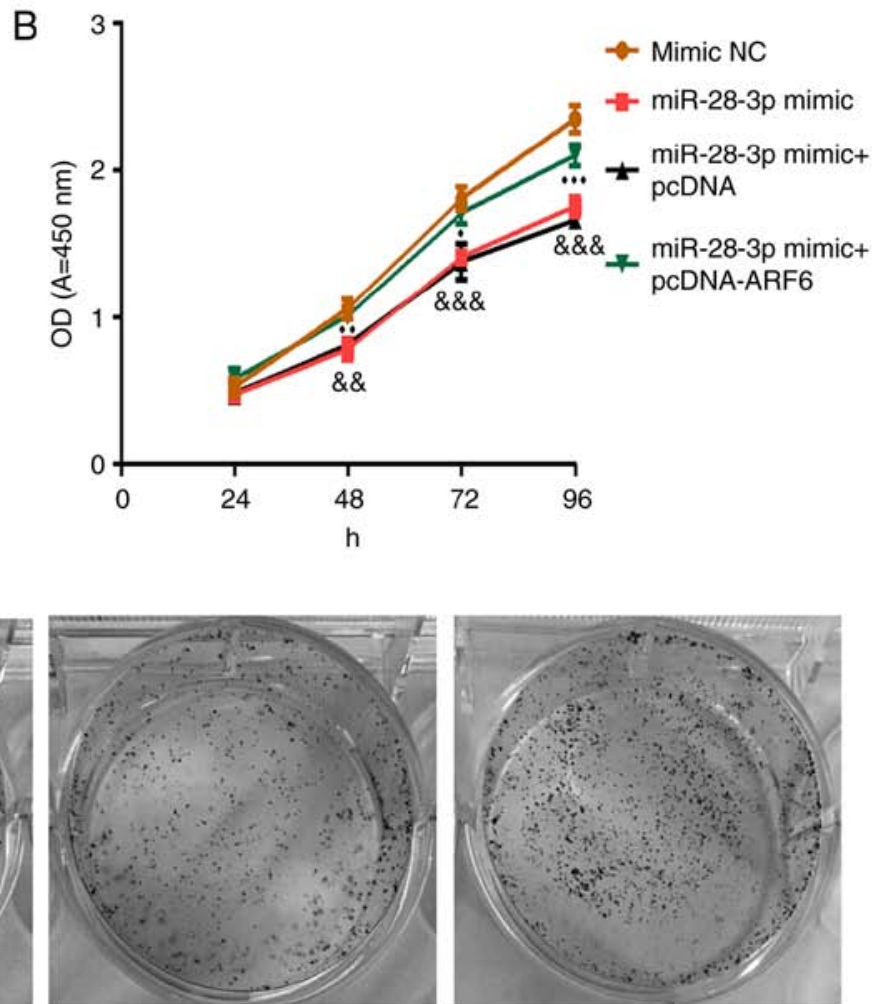

miR-28-3p mimic+pcDNA

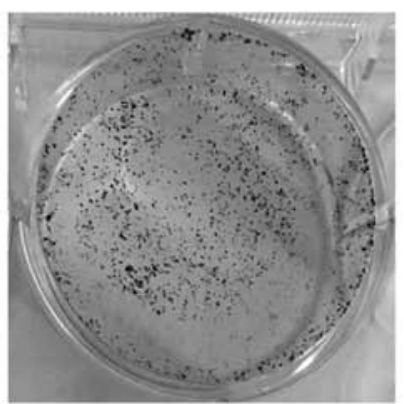

miR-28-3p mimic+pcDNA-ARF6

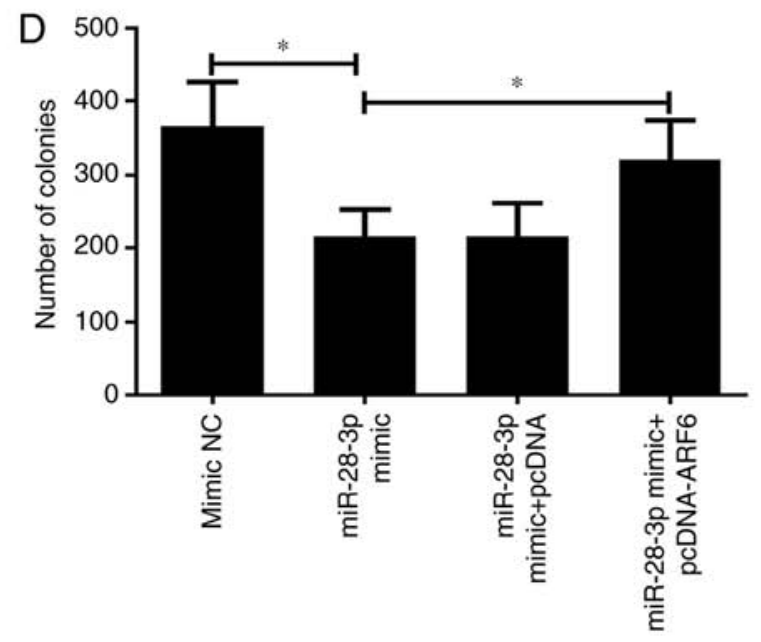

Figure 7. Proliferation of DU145 cells following transfection with the miR-28-3p mimic and ARF6 overexpression vector. (A) Relative expression levels of ARF6 in DU145 cells transfected with pcDNA-ARF6 were detected using reverse transcription-quantitative PCR. ${ }^{* * *} \mathrm{P}<0.001$ vs. pcDNA. (B) Cell Counting Kit- 8 assay was performed to determine the effect of miR-28-3p and ARF6 on cell proliferation. ${ }^{\text {\&\&}} \mathrm{P}<0.01$, and ${ }^{\& \& \&} \mathrm{P}<0.001 \mathrm{vs}$. mimic $\mathrm{NC} ;{ }^{*} \mathrm{P}<0.05,{ }^{* *} \mathrm{P}<0.01$, and ${ }^{* * *} \mathrm{P}<0.001$ vs. miR-28-3p mimic + pcDNA. (C) Colony forming assay was used to detect the formation of cell colonies. (D) Semi-quantification of the results from $(\mathrm{C}) .{ }^{*} \mathrm{P}<0.05$. Colony formation was inhibited in the miR-28-3p mimic group compared with that in the mimic NC group, whereas colony formation was promoted in the miR-28-3p mimic + pcDNA-ARF6 group compared with that in the miR-28-3p mimic + pcDNA group. miR, microRNA; ARF6, ADP-ribosylation factor 6; NC, negative control; OD, optical density; pcDNA, pcDNA3.1.

In the present study, the expression levels of miR-28-3p were found to be downregulated in PCa cells compared with those in RWPE-1 cells; thus, it was hypothesized that miR-28-3p may play a role in the development of PCa. To confirm this hypothesis, miR-28-3p-overexpressing and -knockdown models were established in PCa cells, and miR-28-3p overexpression was discovered to inhibit the cell proliferation, migration and invasion, and induce the apoptosis of PCa cells. miR-28-3p knockdown was found to promote the cell proliferation, migration and invasion, whilst inhibiting the apoptosis of PCa cells. These results indicated that miR-28-3p may serve as a tumor suppressor in PCa and could represent a target for PCa treatment.

To further investigate the mechanism of miR-28-3p in PCa, potential targets of miR-28-3p were predicted using bioinformatics software and ARF6 was identified as a candidate target gene of miR-28-3p. Subsequently, ARF6 was confirmed as a direct target of miR-28-3p using a dual luciferase reporter 

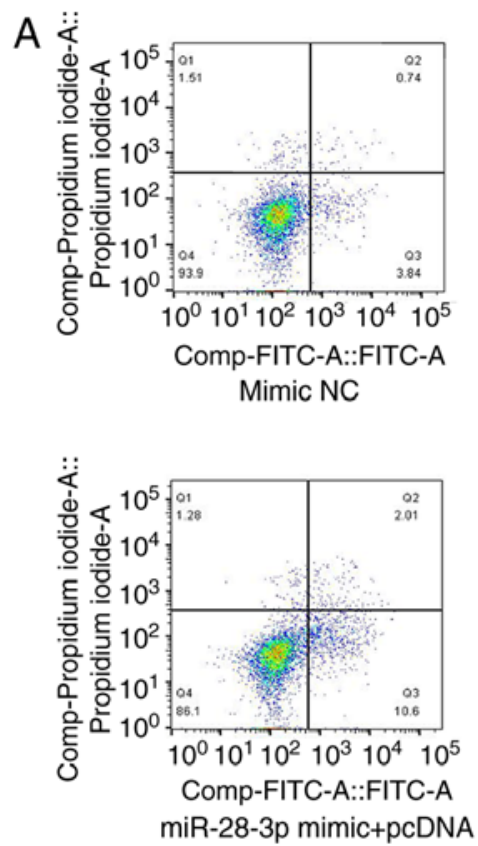
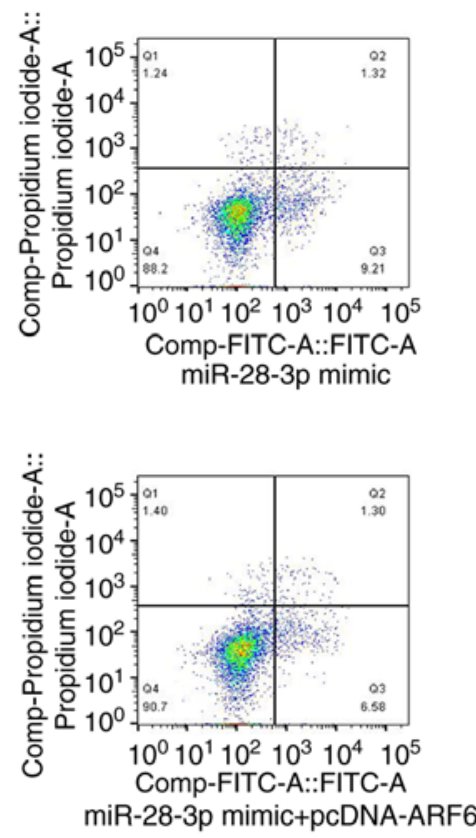

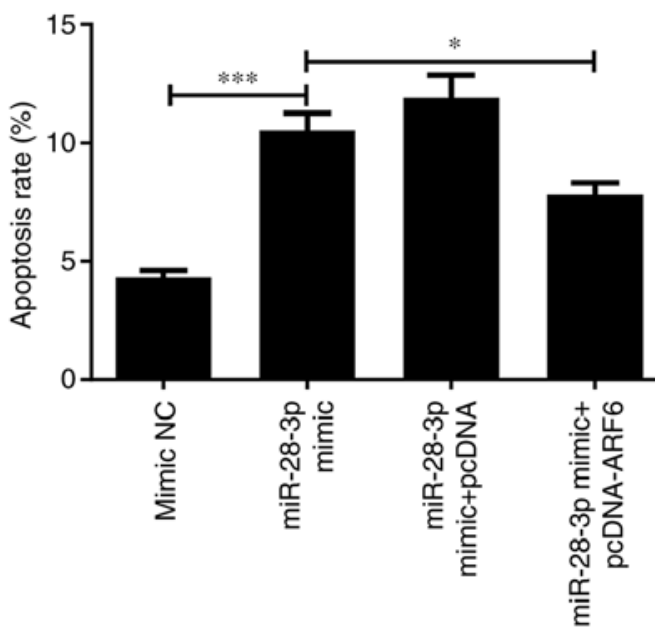

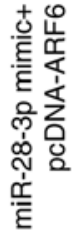
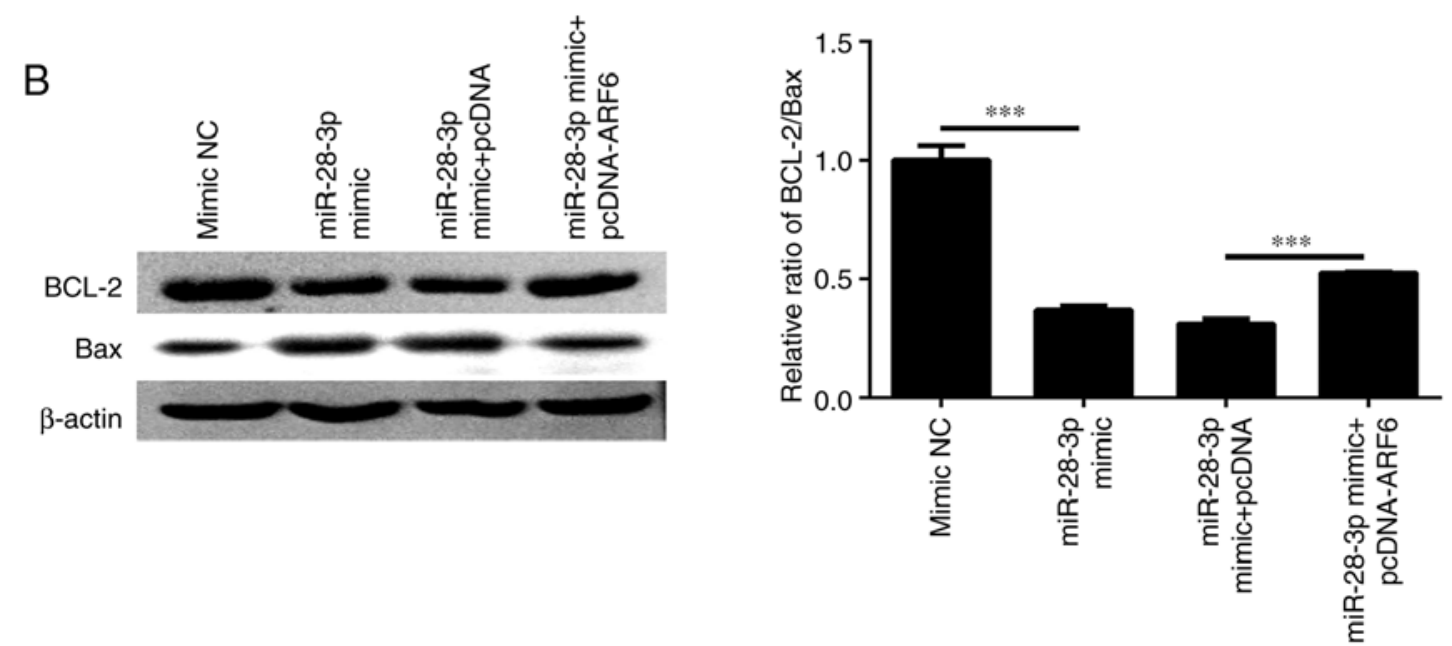

Figure 8. Apoptosis of DU145 cells following transfection of the miR-28-3p mimic and ARF6 overexpression vector. (A) Flow cytometry was used to assess apoptosis. The apoptotic rate was significantly increased in the miR-28-3p mimic group compared with that in the mimic NC group, whereas the miR-28-3p mimic + pcDNA-ARF6 group exhibited significantly inhibited apoptosis levels compared with the miR-28-3p mimic group. (B) Western blotting was used to detect the expression of protein related with cell apoptosis. The ratio of Bcl-2/Bax was markedly elevated in miR-28-3p mimic + pcDNA-ARF6 group compared with that in the miR-28-3p mimic + pcDNA group. ${ }^{*} \mathrm{P}<0.05,{ }^{* * *} \mathrm{P}<0.001$. miR, microRNA; ARF6, ADP-ribosylation factor 6; pcDNA, pcDNA3.1; NC, negative control.

assay, RT-qPCR and western blotting. ARF6 is a small GTPase that mainly regulates membrane trafficking and actin remodeling (22). Previous studies have shown that the upregulated expression of ARF6 may be closely associated with the invasion, migration and metastasis of multiple malignant tumor types (23), such as glioma (24), melanoma (25), breast cancer (26), lung cancer (27) and PCa (28). Shan et al (14) also reported that the knockdown of ARF6 effectively inhibited the proliferation, migration and invasion of PC-3 cells. Thus, miR-28-3p was hypothesized to affect PCa cell behavior via targeting ARF6 expression. In the present study, rescue experiments revealed that ARF6 overexpression could reverse the effect of the miR-28-3p mimic on proliferation, apoptosis, migration and invasion. These data indicated that ARF6 may be involved in miR-28-3p-mediated PCa progression.
Erk1/2 is a member of the mitogen-activated protein kinase signaling pathway, and Erk1/2 phosphorylation has been found to promote the proliferation, migration and invasion of PCa cells (29). Rac1, one of the best-characterized members of the small GTPase family, has been reported to be involved in the organization of the actin cytoskeleton, cell proliferation, tumorigenesis and metastasis (30). ARF6 has also been identified as a potent modulator of Erk and Rac1 activity. Hu et al (31) reported that ARF6 regulated glioma cell migration and invasion via a Rac1-dependent pathway. Tague et al (32) revealed that ARF6 promoted melanoma cell invasion by enhancing Erk1/2 phosphorylation. In hepatocellular carcinoma cells, the knockdown of ARF6 inhibited cell migration and invasion by decreasing Erk1/2 phosphorylation levels and Rac1 activity (33). In PC-3 PCa cells, the knockdown 


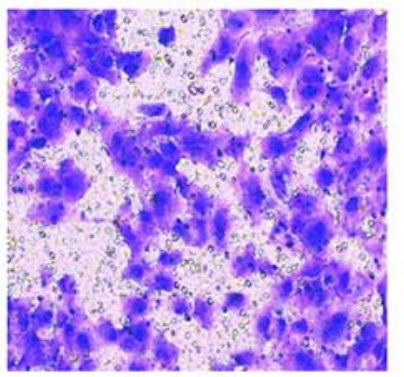

Mimic NC

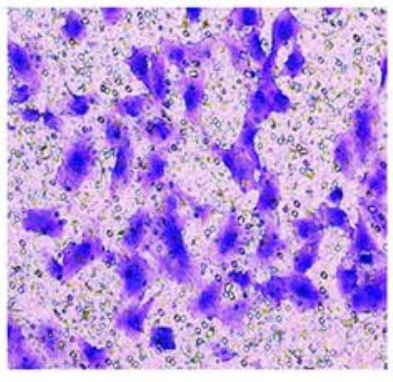

miR-28-3p mimic+ pcDNA

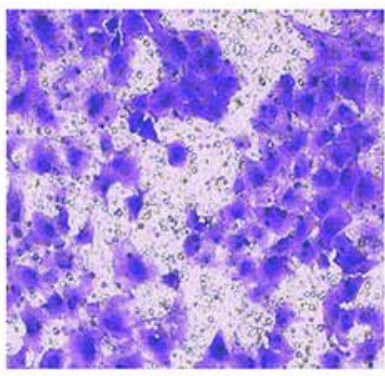

Mimic NC

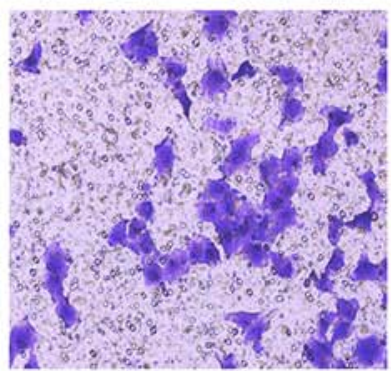

miR-28-3p mimic+

pcDNA

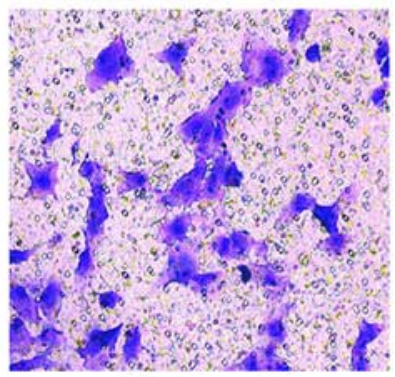

miR-28-3p mimic
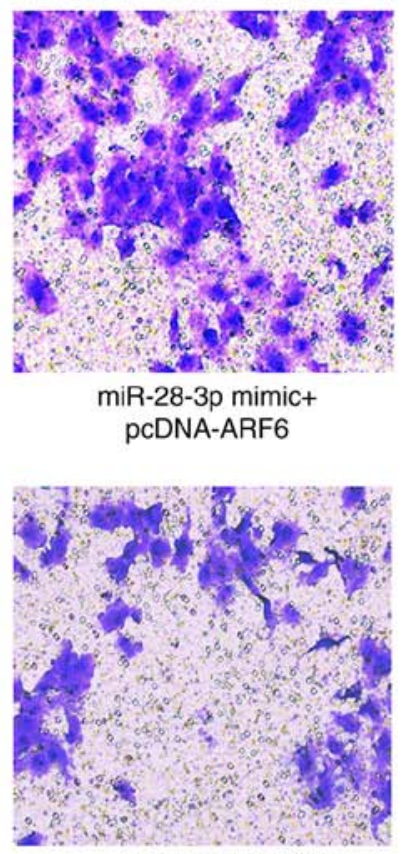

miR-28-3p mimic

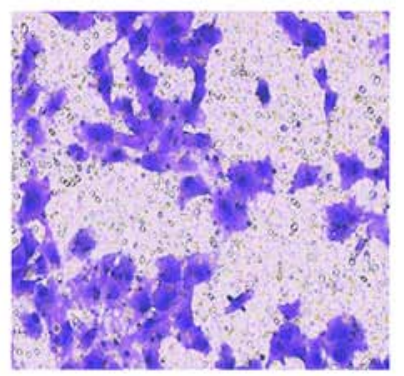

miR-28-3p mimic+

pcDNA-ARF6
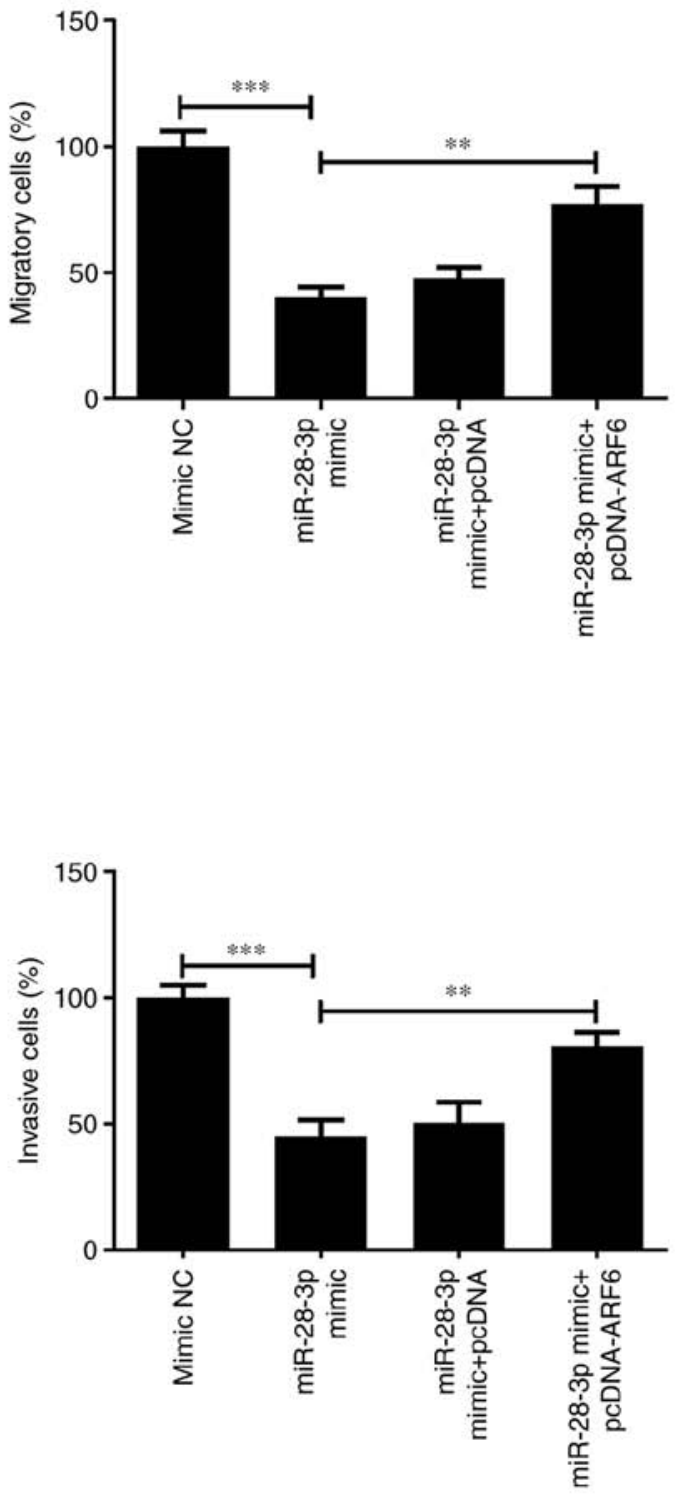

Figure 9. Migration and invasion of DU145 cells following transfection with the miR-28-3p mimic and pcDNA-ARF6 were measured using Transwell assays. The migratory and invasive abilities of cells in the miR-28-3p mimic group were significantly inhibited compared with those in the mimic NC group, whereas the migration and invasion of cells in the miR-28-3p + pcDNA-ARF6 group were significantly increased compared with those in the miR-28-3p mimic group. Magnification, $\mathrm{x} 400 .{ }^{* *} \mathrm{P}<0.01,{ }^{* * *} \mathrm{P}<0.001$. miR, microRNA; pcDNA, pcDNA3.1; ARF6, ADP-ribosylation factor 6; NC, negative control.

of ARF6 inhibited proliferation, migration and invasion by downregulating p-Erk1/2 and Rac1 expression (14). Thus, the present study sought to determine whether miR-28-3p regulated p-Erk1/2 and Rac1 expression by targeting ARF6 in PCa. Western blotting showed that transfection with the miR-28-3p mimic downregulated $\mathrm{p}$-Erk1/2 and Rac1 protein expression levels, indicating that miR-28-3p may suppress $p-E r k 1 / 2$ and Rac1 in PCa. Furthermore, rescue experiments revealed that the overexpression of ARF6 attenuated the inhibitory effects of the miR-28-3p mimic on p-Erk1/2 and Rac1. Taken together, these results suggested that miR-28-3p may suppress p-Erk1/2 and Rac1 expression, at least partly, by targeting ARF6 in PCa.

In conclusion, the present results suggested that miR-28-3p may act as a tumor suppressor gene in $\mathrm{PCa}$ and may be involved in PCa by targeting ARF6 to downregulate the expression of p-Erk1/2 and Rac1. Therefore, miR-28-3p may represent a novel target for the treatment of PCa. However, this study has its own limitations. For example, the effect of miR-28-3p in 

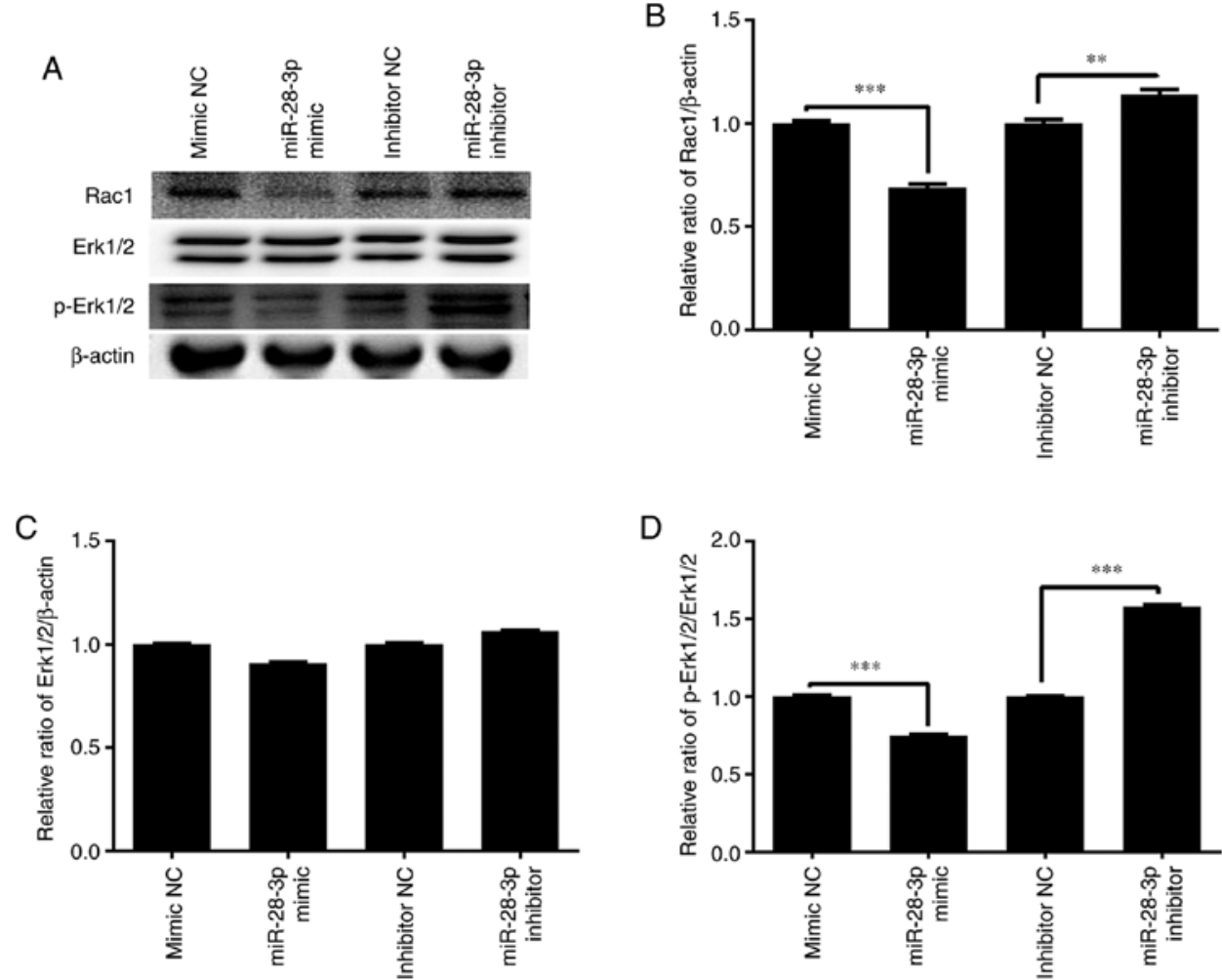

Figure 10. Effect of miR-28-3p overexpression and knockdown on p-Erk1/2 and Rac1. (A) Western blotting was performed to determine the effect of miR-28-3p overexpression and knockdown on p-Erk1/2 and Rac1 expression. Protein expression levels of (B) Rac1, (C) Erk1/2 (molecular weight at 44 and $42 \mathrm{kDa}$, respectively) and (D) p-Erk1/2 (molecular weight at 44 and $42 \mathrm{kDa}$, respectively) in DU145 cells following transfection with the miR-28-3p mimic or inhibitor. ${ }^{* *} \mathrm{P}<0.01,{ }^{* * *} \mathrm{P}<0.001$. miR, microRNA; $\mathrm{p}$-, phosphorylated; NC, negative control.
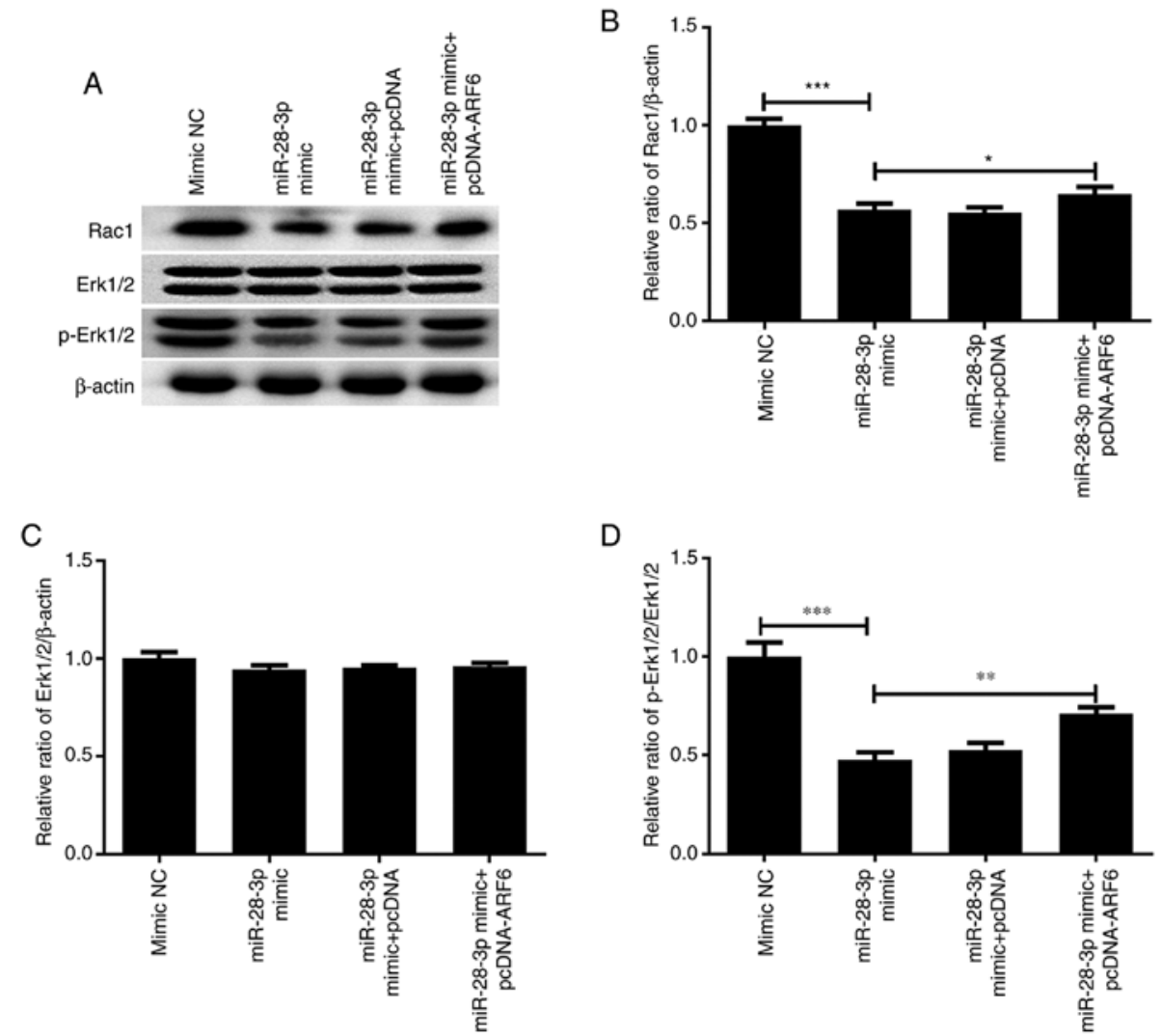

Figure 11. Effect of miR-28-3p and ARF6 overexpression on p-Erk1/2 and Rac1 expression. (A) Western blotting was performed to analyze the effect of miR-28-3p and ARF6 overexpression on p-Erk1/2 and Rac1 expression. Protein expression levels of (B) Rac1, (C) Erk1/2 (molecular weight at 44 and $42 \mathrm{kDa}$, respectively) and (D) p-Erk1/2 (molecular weight at 44 and $42 \mathrm{kDa}$, respectively) in DU145 cells after transfection with miR-28-3p mimic and pcDNA-ARF6. ${ }^{*} \mathrm{P}<0.05,{ }^{* *} \mathrm{P}<0.01,{ }^{* * *} \mathrm{P}<0.001$. miR, microRNA; NC, negative control; pcDNA, pcDNA3.1; ARF6, ADP-ribosylation factor 6; p-, phosphorylated. 
PCa was only explored in PCa DU145 cells and will need to be investigated in different cell lines in the future to verify the current findings.

\section{Acknowledgements}

Not applicable.

\section{Funding}

The present study was supported by grant from the Natural Science Foundation of Fujian Province (grant no. 2018J01219).

\section{Availability of data and materials}

The datasets used and/or analyzed during the current study are available from the corresponding author on reasonable request.

\section{Authors' contributions}

JZ and YY conceived and designed the experiments. HL and SY performed the experiments and analyzed the data. JZ and YY wrote and revised the manuscript. All authors read and approved the final manuscript. JZ and YY confirm the authenticity of all the raw data.

\section{Ethics approval and consent to participate}

Not applicable.

\section{Patient consent for publication}

Not applicable.

\section{Competing interests}

The authors declare that they have no competing interests.

\section{References}

1. Bray F, Ferlay J, Soerjomataram I, Siegel RL, Torre LA and Jemal A: Global cancer statistics 2018: GLOBOCAN estimates of incidence and mortality worldwide for 36 cancers in 185 countries. CA Cancer J Clin 68: 394-424, 2018.

2. Nagaya $\mathrm{N}$ and Horie S: Endocrine therapy for prostate cancer. Clin Calcium 28: 1527-1533, 2018 (In Japanese).

3. Nead KT, Sinha S and Nguyen PL: Androgen deprivation therapy for prostate cancer and dementia risk: A systematic review and meta-analysis. Prostate Cancer Prostatic Dis 20: 259-264, 2017.

4. Fujita $\mathrm{K}$ and Nonomura N: Role of androgen receptor in prostate cancer: A review. World J Mens Health 37: 288-295, 2019.

5. Carruba G: Estrogens in prostate cancer. In: Prostate Cancer: A Comprehensive Perspective. Tewari, AK (ed). Springer, London, pp369-381, 2013.

6. Guo H, Ingolia NT, Weissman JS and Bartel DP: Mammalian microRNAs predominantly act to decrease target mRNA levels. Nature 466: 835-840, 2010

7. Tutar Y: miRNA and cancer; computational and experimental approaches. Curr Pharm Biotechnol 15: 429, 2014

8. Krol J, Loedige I and Filipowicz W: The widespread regulation of microRNA biogenesis, function and decay. Nat Rev Genet 11: 597-610, 2010

9. Vanacore D, Boccellino M, Rossetti S, Cavaliere C, D'Aniello C, Di Franco R, Romano FJ, Montanari M, La Mantia E, Piscitelli R, et al: Micrornas in prostate cancer: An overview. Oncotarget 8: 50240-50251, 2017.
10. Bonci D, Coppola V, Musumeci M, Addario A, Giuffrida R, Memeo L, D'Urso L, Pagliuca A, Biffoni M, Labbaye C, et al: The miR-15a-miR-16-1 cluster controls prostate cancer by targeting multiple oncogenic activities. Nat Med 14: 1271-177, 2008.

11. Noonan EJ, Place RF, Pookot D, Basak S, Whitson JM, Hirata H, Giardina C and Dahiya R: miR-449a targets HDAC-1 and induces growth arrest in prostate cancer. Oncogene 28: 1714-1724, 2009.

12. Fletcher CE, Sulpice E, Combe S, Shibakawa A, Leach DA Hamilton MP, Chrysostomou SL, Sharp A, Welti J, Yuan W, et al: Androgen receptor-modulatory microRNAs provide insight into therapy resistance and therapeutic targets in advanced prostate cancer. Oncogene 38: 5700-5724, 2019.

13. Fuse M, Kojima S, Enokida H, Chiyomaru T, Yoshino $H$ Nohata N, Kinoshita T, Sakamoto S, Naya Y, Nakagawa M, et al: Tumor suppressive microRNAs (miR-222 and miR-31) regulate molecular pathways based on microRNA expression signature in prostate cancer. J Hum Genet 57: 691-699, 2012.

14. Shan XW, Lv SD, Yu XM, Hu ZF, Zhang JJ, Wang GF and Wei Q: Small RNA interference-mediated ADP-ribosylation factor 6 silencing inhibits proliferation, migration and invasion of human prostate cancer PC-3 cells. Nan Fang Yi Ke Da Xue Xue Bao 36: 735-743, 2016 (In Chinese).

15. Hongu T, Yamauchi Y, Funakoshi Y, Katagiri N, Ohbayashi N and Kanaho Y: Pathological functions of the small GTPase Arf6 in cancer progression: Tumor angiogenesis and metastasis. Small GTPases 7: 47-53, 2016.

16. Livak KJ and Schmittgen TD: Analysis of relative gene expression data using real-time quantitative PCR and the 2(-Delta Delta C(T)) method. Methods 25: 402-408, 2001.

17. Han W and Li J: Structure-activity relationship analysis of 3-phenylpyrazole derivatives as androgen receptor antagonists. J Biomol Struct Dyn 38: 2582-2591, 2020.

18. Luu HN, Lin HY, Sørensen KD, Ogunwobi OO, Kumar N, Chornokur G, Phelan C, Jones D, Kidd L, Batra J, et al: miRNAs associated with prostate cancer risk and progression. BMC Urol 17: 18, 2017.

19. Almeida MI, Nicoloso MS, Zeng L, Ivan C, Spizzo R, Gafà R, Xiao L, Zhang X, Vannini I, Fanini F, et al: Strand-specific miR-28-5p and miR-28-3p have distinct effects in colorectal cancer cells. Gastroenterology 142: 886-896.e9, 2012.

20. Huang Z, Zhang L, Zhu D, Shan X, Zhou X, Qi LW, Wu L, Zhu J, Cheng $\mathrm{W}$, Zhang $\mathrm{H}$, et al: A novel serum microRNA signature to screen esophageal squamous cell carcinoma. Cancer Med 6: 109-119, 2017.

21. Pospisilova S, Pazourkova E, Horinek A, Brisuda A, Svobodova I, Soukup V, Hrbacek J, Capoun O, Hanus T, Mares J, et al: MicroRNAs in urine supernatant as potential non-invasive markers for bladder cancer detection. Neoplasma 63: 799-808, 2016.

22. Hongu $\mathrm{T}$ and Kanaho $\mathrm{Y}$ : Versatile in vivo functions of the small GTPase Arf6. Seikagaku 88: 78-85, 2016 (In Japanese).

23. Li R, Peng C, Zhang X, Wu Y, Pan S and Xiao Y: Roles of Arf6 in cancer cell invasion, metastasis and proliferation. Life Sci 182: 80-84, 2017.

24. Li M, Wang J, Ng SS, Chan CY, He ML, Yu F, Lai L, Shi C, Chen Y, Yew DT, et al: Adenosine diphosphate-ribosylation factor 6 is required for epidermal growth factor-induced glioblastoma cell proliferation. Cancer 115: 4959-4972, 2009.

25. Grossmann AH, Yoo JH, Clancy J, Sorensen LK, Sedgwick A, Tong Z, Ostanin K, Rogers A, Grossmann KF, Tripp SR, et al: The small GTPase ARF6 stimulates $\beta$-catenin transcriptional activity during WNT5A-mediated melanoma invasion and metastasis. Sci Signal 6: ra14, 2013.

26. Hashimoto S, Onodera Y, Hashimoto A, Tanaka M, Hamaguchi M, Yamada A and Sabe H: Requirement for Arf6 in breast cancer invasive activities. Proc Natl Acad Sci USA 101: 6647-6652, 2004.

27. Menju T, Hashimoto S, Hashimoto A, Otsuka Y, Handa H, Ogawa E, Toda Y, Wada H, Date H, Sabe H, et al: Engagement of overexpressed Her2 with GEP100 induces autonomous invasive activities and provides a biomarker for metastases of lung adenocarcinoma. PLoS One 6: e25301, 2011.

28. Liang C, Qin Y, Zhang B, Ji S, Shi S, Xu W, Liu J, Xiang J, Liang D, Hu Q, et al: ARF6, induced by mutant Kras, promotes proliferation and Warburg effect in pancreatic cancer. Cancer Lett 388: 303-311, 2017.

29. Klemke RL, Cai S, Giannini AL, Gallagher PJ, de Lanerolle P and Cheresh DA: Regulation of cell motility by mitogen-activated protein kinase. J Cell Biol 137: 481-492, 1997.

30. Burridge $\mathrm{K}$ and Wennerberg $\mathrm{K}$ : Rho and Rac take center stage. Cell 116: 167-179, 2004 
31. Hu B, Shi B, Jarzynka MJ, Yiin JJ, D'Souza-Schorey C and Cheng SY: ADP-ribosylation factor 6 regulates glioma cell invasion through the IQ-domain GTPase-activating protein 1-Racl-mediated pathway. Cancer Res 69: 794-801, 2009.

32. Tague SE, Muralidharan V and D'Souza-Schorey C: ADP-ribosylation factor 6 regulates tumor cell invasion through the activation of the MEK/ERK signaling Pathway. Proc Natl Acad Sci USA 101: 967I-9676, 2004.
33. Hu Z, Du J, Yang L, Zhu Y, Yang Y, Zheng D, Someya A, Gu L and Lu X: GEP100/Arf6 is required for epidermal growth factor-induced ERK/Rac 1 signaling and cell migration in human hepatoma HepG2 cells. PLoS One 7: e38777, 2012.

(i) (3) This work is licensed under a Creative Commons Attribution-NonCommercial-NoDerivatives 4.0 International (CC BY-NC-ND 4.0) License. 